\title{
Exercício contínuo e intermitente: Efeitos do treinamento e do destreinamento sobre o peso corporal e o metabolismo muscular de ratos obesos
}

\author{
Larissa Braga \\ Maria Mello \\ Fúlvia Manchado \\ Claudio Gobatto
}

https://doi.org/10.5628/rpcd.06.02.160

\author{
Universidade Estadual Paulista \\ Instituto de Biociências \\ Departamento de Educação Física \\ Rio Claro \\ São Paulo \\ Brasil
}

\begin{abstract}
RESUMO
Este estudo teve como objetivo comparar os efeitos de programas de treinamento contínuo e intermitente e do destreinamento sobre a adiposidade corporal e o metabolismo muscular de ratos obesos. Foram utilizados ratos Wistar, recém-nascidos, que receberam glutamato monossódio (MSG), via subcutânea, $4 \mathrm{mg} / \mathrm{g}$ peso corporal (p.c.), a cada dois dias, nos primeiros 14 dias de vida. Após o desmame, foram separados em 3 grupos: MSG-SED (sedentário), MSG-CONT (treino contínuo = natação, $45 \mathrm{~min} / \mathrm{dia}, 5$ dias/semana, com sobrecarga de $5 \%$ p.c. durante 10 semanas) e MSG-INT (treino intermitente = natação, 15 seg de atividade/15 seg de repouso, num total de $45 \mathrm{~min}, 5$ dias/semana, com sobrecarga de $15 \%$ do peso corporal). Como controles foram utilizados ratos que receberam solução salina (SAL) separados em 3 grupos: SAL-SED, SALCONT e SAL-INT. Os animais foram avaliados após 12 semanas de treinamento e 8 semanas depois de sua interrupção. Os ratos MSG mostraram maiores teores de gordura na carcaça que os SAL, comprovando a eficácia da droga em causar obesidade. Ambos os protocolos de treino foram eficazes em reduzir significativamente o ganho de peso dos ratos SAL e MSG bem como a produção muscular de lactato dos ratos MSG. Os efeitos dos dois protocolos foram transitórios, uma vez que após o destreinamento os benefícios observados foram revertidos.
\end{abstract}

Palavras-chave: obesidade, treinamento intermitente, treinamento contínuo, glutamato monossódico, rato.

\begin{abstract}
Continuous and intermittent exercise: Effects of training and detraining on body weight and muscle metabolism in obese rats

This study was designed to compare the effects of continuous and intermittent exercise training on body weight, carcass composition and muscle metabolism in obese rats. Obese male Wistar rats (treated with monosodium glutamate-MSG-administration, $4 \mathrm{mg} / \mathrm{g}$ body weight, administered every 2 day, from birth to 14 days of age) were used. After drug administration, the rats were separated into three groups: MSG-SED (sedentary), MSG-CONT (continuous training = swimming, $45 \mathrm{~min} /$ day, 5 days/week, with an overload of $5 \%$ body weight during 12 weeks) and MSG-INT (intermittent training $=15 \mathrm{sec}$ swimming intermitted by $15 \mathrm{sec}$ rest, during $45 \mathrm{~min}$, 5 days/week, with an overload of $15 \%$ body weight during 12 weeks). Rats of the same age and strain, administered with saline (SAL) were used as controls and subdivided into three groups: SALT-SED, SALT-CONT and SALTINT. The animals were evaluated after 12 weeks of training and after 8 weeks of detraining. MSG rats showed higher carcass fat content than SAL rats, indicting the effectiveness of the drug in causing obesity. Both training protocols were effective in reducing significantly body weight gain of SAL and MSG rats as well as the lactate production by the skeletal muscle of the MSG rats. The effects of the two protocols were transitory, since after the detraining period the observed benefits were reverted.
\end{abstract}

Key Words: obesity, intermittent training, continuous training, monosodium glutamate, rat. 


\section{INTRODUÇÃO}

Os estudos envolvendo a obesidade têm-se intensificado nos últimos anos, em função da presença cada vez maior de indivíduos portadores dessa doença, que ganha contornos de epidemia mundial. Os motivos para essa incidência são muitos, contando-se entre eles fatores genéticos, psicológicos, fisiológicos e, especialmente, hábitos alimentares inadequados associados a estilos de vida sedentários decorrentes da vida moderna (7).

Vários modelos de obesidade experimental têm sido propostos a fim de investigar aspectos metabólicos e hormonais envolvidos nesse quadro (35). Os estudos em modelos animais têm sido bastante úteis no estabelecimento das causas e consequências da doença e podem, também, ter importante participação no desenvolvimento de procedimentos mais efetivos para prevenção e tratamento.

Entre os modelos neurais, a obesidade hipotalâmica é a mais bem conhecida. Existem diferentes maneiras de indução da obesidade hipotalâmica, inclusive através de injeções sistêmicas de glutamato monossódico. Animais tratados com essa droga apresentam redução do crescimento corporal, intolerância à glicose e resistência à insulina, entre outras alterações (35).

O exercício físico, por sua vez, tem sido amplamente empregado, isoladamente ou em associação com dietoterapia, no tratamento da obesidade. Embora a utilização do treinamento contínuo, de caráter aeróbio, seja mais difundida, o treinamento intervalado, segundo alguns autores, também pode ser útil em programas de redução ponderal, uma vez que parece induzir maiores adaptações metabólicas mesmo 24 horas após exercício (17). Tem sido relatado, para esse modelo de treinamento, maior transporte de glicose, elevação dos estoques de glicogênio, maior oxidação da glicose e aumento da capacidade de transporte do lactato da fibra muscular para a circulação sanguínea em músculos adaptados $(3,14,19$, $28,31)$. Existem poucas informações quanto ao uso do exercício na prevenção da obesidade e são raros os estudos comparativos entre os efeitos de programas contínuos e intermitentes sobre a gordura corporal e o metabolismo muscular. Mais raras ainda são as pesquisas que abordam os efeitos do destreinamento sobre esses parâmetros.
O presente estudo foi delineado com o objetivo de comparar os efeitos de programas de treinamento físico contínuo e intermitente e do subsequente destreinamento, sobre a gordura corporal e o metabolismo glicídico muscular de ratos jovens com obesidade induzida por glutamato monossódico (MSG).

\section{MATERIAIS E MÉTODOS}

\section{Animais e seu tratamento}

Foram utilizados ratos Wistar, recém-nascidos (obtidos da Universidade Estadual Paulista - UNESP, Campus de Botucatu - SP), que receberam glutamato monossódico (MSG - 4mg/g peso corporal) via subcutânea, a cada dois dias nos primeiros 14 dias de vida. Após o desmame, os animais foram separados em 3 grupos: MSG-SED (sedentário, $n=30$ ), MSGCONT (treino contínuo = natação, $n=30$ ) e MSGINT (treino intervalado $=$ natação, $n=30$ ) e mantidos em gaiolas coletivas, não excedendo quatro animais por gaiola, em ciclo claro/escuro de 12/12 horas. Como controles foram utilizados ratos que receberam solução salina (SAL) e que foram separados também em 3 grupos: SAL-SED $(n=30)$, SALCONT $(n=30)$ e SAL-INT $(n=30)$. Em cada grupo, 20 animais foram avaliados após 12 semanas de treinamento (contínuo e intermitente) ou de vida sedentária, enquanto os 10 restantes foram sacrificados 8 semanas depois. Todos os ratos tiveram livre acesso à água e ao alimento (ração comercial para roedores). Antes do início dos programas de treinamento, os animais designados aos grupos sedentários e treinados passaram por período de adaptação ao meio líquido, bem como à colocação de sobrecarga em seu dorso, durante uma semana. Após isso, os treinados foram submetidos aos programas designados, enquanto os sedentários (MSG-SED e SALSED) foram manipulados e mantidos em água rasa ( $5 \mathrm{~cm}$ de profundidade) no mesmo horário e tempo de duração dos treinados, visando submetê-los às mesmas condições dos grupos experimentais. Todos os procedimentos foram conduzidos seguindo as normas éticas de experimentação animal, vigentes atualmente no Brasil.

\section{Protocolos de treinamento Programa contínuo}

O programa contínuo consistiu de 45 minutos de natação com sobrecarga de $5 \%$ do peso corporal do 
animal, cinco dias por semana, durante 12 semanas consecutivas, em recipiente contendo água mantida a $32 \pm 1^{\circ} \mathrm{C}$, de acordo com protocolos previamente definidos na literatura $(13,26)$.

\section{Programa intervalado}

O programa intervalado consistiu num tempo total de 45 minutos de natação, sendo alternados 15 segundos de trabalho suportando sobrecarga de $15 \%$ do peso corporal com 15 segundos de repouso, cinco dias por semana, durante 12 semanas, em recipiente contendo água mantida a $32 \pm 1^{\circ} \mathrm{C}$, de acordo com protocolo definido na literatura (36). Em ambos os programas, contínuo e intermitente, durante a primeira semana de treinamento, houve adaptação progressiva à sobrecarga utilizada em cada caso.

\section{Avaliações prévias ao sacrifício dos animais Parâmetros gerais}

Os animais foram pesados e medidos (focinho-ânus) no início e no final de cada período experimental para a determinação das variações ponderais (ganho ou perda de peso corporal) e do comprimento linear final do período, respectivamente. A ingestão alimentar dos ratos foi registrada uma vez por semana, por meio da diferença entre a quantidade de alimento ofertada num dia e a quantidade restante no comedouro no dia seguinte, o que permitiu a determinação da ingestão alimentar média de cada período.

\section{Avaliações após o sacrifício dos animais}

Metabolismo da glicose pelo músculo sóleo isolado Após o sacrifício por decapitação, as patas traseiras foram retiradas e o músculo sóleo foi removido. Os tendões distal e proximal desse músculo foram liberados e com um bisturi foi efetuado um corte longitudinal em sua linha mediana. A seguir, a preparação foi pesada e as fatias com peso entre 25 e $35 \mathrm{mg}$ foram submetidas ao procedimento de incubação descrito por Mello et al (26), modificado.

As fatias de músculo sóleo ( 25 e $35 \mathrm{mg}$ ) foram colocadas em frascos de cintilação contendo $1,5 \mathrm{ml}$ de tampão Krebs-Ringer bicarbonato e submetidos a 30 minutos de pré-incubação sob agitação em banho tipo Dubinoff a 60 rpm e contínuo gaseamento com $\mathrm{O}_{2} / \mathrm{CO}_{2}(95 \% / 5 \%)$. Após esse período, as fatias do músculo foram transferidas para novos frascos de cintilação (frasco externo), em cujo interior foram instalados pequenos tubos em forma de concha (frasco interno) com uma haste reta de aproximadamente $3 \mathrm{~cm}$ de comprimento que se insere nas tampas de borracha do frasco externo.

Cada frasco externo continha $1,5 \mathrm{ml}$ de tampão Krebs-Ringer e cada frasco interno $700 \mu \mathrm{l}$ de hiamina 10x. Após 60 minutos de incubação nesse sistema, com gaseamento durante os 15 primeiros minutos, foram adicionados $100 \mu \mathrm{l}$ de ácido tricloroacético (TCA) $25 \%$ ao frasco externo visando a liberação de $\mathrm{CO}_{2}$. A preparação foi mantida por mais 3 horas no sistema. Decorrido esse tempo, $200 \mu \mathrm{l}$ do líquido contido no frasco interno foram retirados para a determinação do $\mathrm{CO}_{2}$ produzido. O meio de incubação acidificado contido no frasco externo foi armazenado para determinação do lactato e a fatia de músculo imediatamente digerida em 0,5 ml de $\mathrm{KOH}$ (38) para dosagem do glicogênio muscular (11). A temperatura na pré-incubação e incubação foi de $37^{\circ} \mathrm{C}$ (Figura 1).

O tampão Krebs-Ringer, base dos meios de pré-incubação e incubação, constituiu de: NACL 06\%, HEPES 6,64mM, KCL 0,032\%, CACL $21,14 \mathrm{nM}$, $\mathrm{KH}_{2} \mathrm{PO}_{4}$ 0,015\%, NAHCO $30,19 \%, \mathrm{MgSO}_{4}$ 0,03\%. A solução assim preparada foi gaseada durante 20 a 30 minutos em $\mathrm{O}_{2} / \mathrm{CO}_{2}(95 \% / 5 \%)$ e o $\mathrm{pH}$ ajustado a 7,4. A esta solução foram adicionados 20 volumes de albumina sérica bovina livre de gordura. Ao meio de pré-incubação foi adicionado piruvato de sódio para a concentração de $5 \mathrm{mM}$. Ao meio de incubação, foi adicionada glicose $(5,5 \mathrm{mM})$ contendo $\left[\mathrm{U}_{-14} \mathrm{C}\right]$ glicose $(0,25 \mathrm{mCi} / \mu \mathrm{l}),\left[{ }^{3} \mathrm{H}\right] 2$-deoxyglicose $(2 \mathrm{DG}=0,5$ $\mathrm{mCi} / \mu \mathrm{l})$ e insulina $(100 \mathrm{mUI} / \mu \mathrm{l})$. Feitas as adições, o $\mathrm{pH}$ foi ajustado a 7,4 e os meios transferidos para os frascos que foram selados e equilibrados no banho a $37^{\circ} \mathrm{C}$ sob gaseamento em $\mathrm{O}_{2} / \mathrm{CO}_{2}$ $(95 \% / 5 \%)$ durante pelo menos 15 minutos. Fatias do mesmo músculo, com peso semelhante àquelas incubadas, foram utilizadas para determinação da concentração controle de glicogênio. 


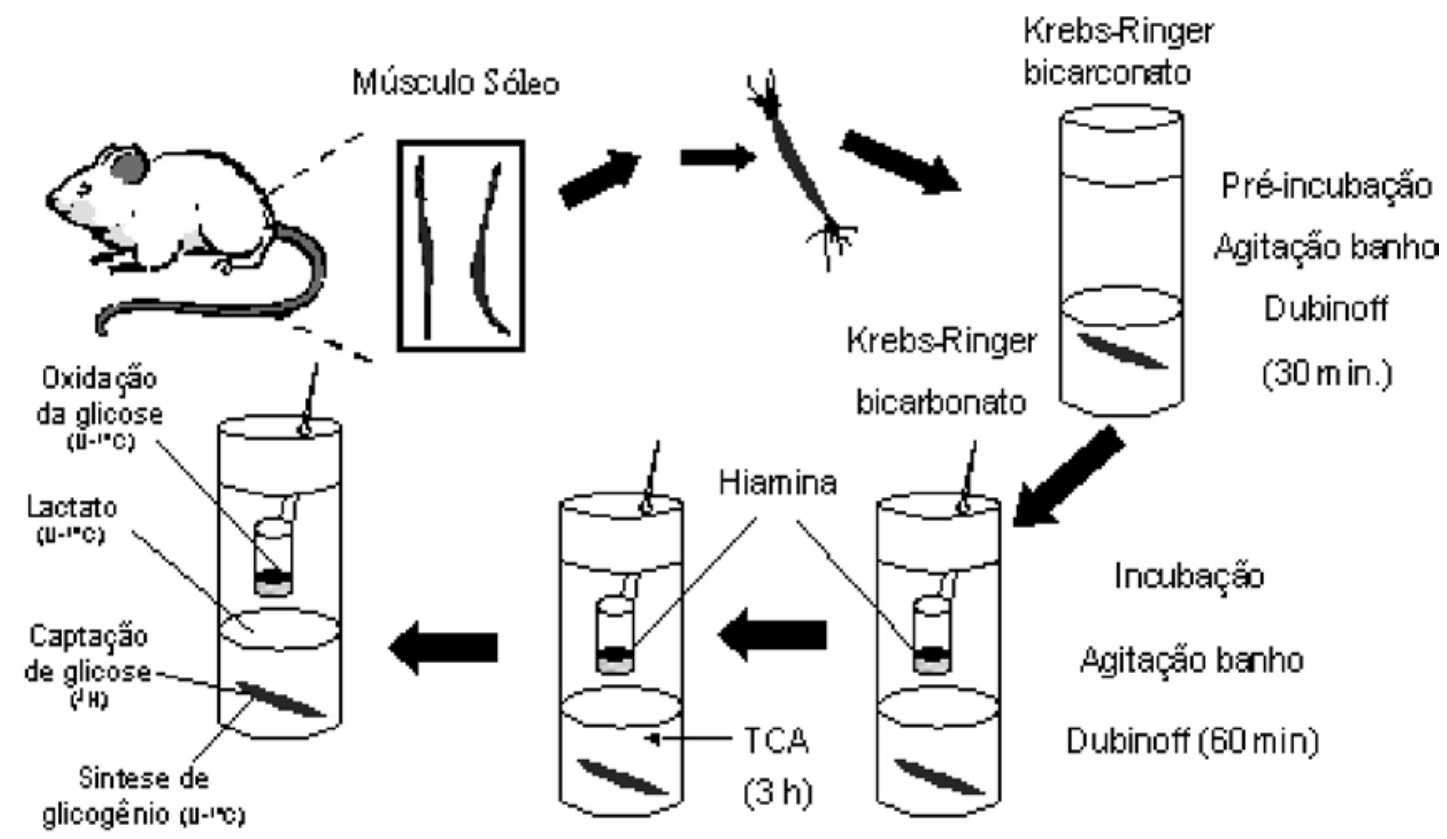

Figura 1. Etapas do procedimento de incubação.

Foram avaliadas a captação de glicose, utilizando-se a 2-DG como marcador, e a incorporação do ${ }^{14} \mathrm{C}$ a glicogênio (síntese), medindo-se a radioatividade do ${ }^{14} \mathrm{C}$ da glicose e ${ }^{3} \mathrm{H}$ da $2-\mathrm{DG}$ contidas, respectivamente, no precipitado e na fase alcoólica da extração do glicogênio, através de contador de partículas beta. O lactato radioativo liberado no meio de incubação foi determinado por separação de metabólitos em coluna de troca iônica (Dowex-2, Sigma), o que representa um índice do transporte de glicose nessas condições. Para a estimativa da glicose oxidada (produção de $\mathrm{CO}_{2}$ ), foi determinada a radioatividade do ${ }^{14} \mathrm{C}$ presente no líquido (hiamina) coletado do frasco interno do sistema de incubação.

\section{Composição química da carcaça}

Após sacrifício dos animais as carcaças foram evisceradas, pesadas e secas até peso constante em estufa a $100^{\circ} \mathrm{C}$. Foram então homogenizadas em liquidificador com benzeno sofrendo várias lavagens com esse solvente para a remoção da gordura. A carcaça livre de gordura foi seca até peso constante em estufa a $100^{\circ} \mathrm{C}$. O pó seco e desengordurado foi pesado. O conteúdo de gordura foi calculado por diferença de peso (23).

\section{Peso do tecido adiposo epididimal}

Por terem sido utilizados ratos machos no estudo, o tecido adiposo epididimal dos animais, de característica visceral e facilmente delimitado, foi totalmente removido e pesado em balança analítica com precisão de $10^{-4}$ gramas.

\section{Análise estatística}

Foi realizada através da análise de variância de duas entradas, sendo avaliados os efeitos da obesidade induzida por glutamato monossódico e do treinamento físico. Quando necessário foi utilizado o teste "post-hoc" Newman-Keuls para a comparação entre os grupos. Em todos os casos, o nível de significância foi pré-fixado em $5 \%$.

\section{RESULTADOS}

Os valores referentes ao ganho de peso e ao comprimento corporal dos ratos MSG foram significativamente inferiores em relação aos animais controles equivalentes. Na etapa de destreinamento, apenas os ratos MSG-SED mantiveram menor ganho de peso que os demais (Tabela 1). 
Tabela 1. Ganho de peso ( $\mathrm{g}$ ] e ingestão alimentar média $(\mathrm{g} / 100 \mathrm{~g}$ dia) durante os períodos de treinamento e destreinamento e comprimento corporal $(\mathrm{cm})$ ao final desses períodos.

\begin{tabular}{|c|c|c|c|c|c|c|}
\hline \multicolumn{7}{|l|}{ TREINAMENTO } \\
\hline \multirow[t]{2}{*}{ Grupos } & SAL & SAL & SAL & MSG & MSG & MSG \\
\hline & SED & CONT & INT & SED & CONT & INT \\
\hline Ganho & 309,1 & $251,4^{2}$ & $276,5^{a b}$ & $240,4^{2}$ & $200,8^{\text {bd }}$ & $202,0^{\text {cd }}$ \\
\hline de Peso & $\pm 33,7$ & $\pm 17,8$ & $\pm 36,8$ & $\pm 39,8$ & $\pm 29,0$ & $\pm 34,30$ \\
\hline \multirow[t]{2}{*}{ Comprimento Corporal } & 23,9 & 23,0 & 23,2 & $21,6^{2}$ & $21,3^{b}$ & $21,0^{c}$ \\
\hline & $\pm 1,5$ & $\pm 0,9$ & $\pm 1,3$ & $\pm 1,0$ & $\pm 1,0$ & $\pm 0,6$ \\
\hline \multirow[t]{2}{*}{ Ingestão Alimentar } & 7,8 & 8,7 & 8,2 & 7,5 & 8,8 & 8,1 \\
\hline & $\pm 0,1$ & $\pm 2,0$ & $\pm 0,4$ & $\pm 0,4$ & $\pm 1,1$ & $\pm 1,0$ \\
\hline \multicolumn{7}{|l|}{ DESTREINAMENTO } \\
\hline Ganho & 125,6 & 143,9 & 104,5 & $47,9^{2}$ & $102,4^{d}$ & $106,4^{d}$ \\
\hline de Peso & $\pm 48,0$ & $\pm 34,1$ & $\pm 53,7$ & $\pm 10,4$ & $\pm 34,3$ & $\pm 36,4$ \\
\hline \multirow[t]{2}{*}{ Comprimento Corporal } & 23,1 & 25,0 & 25,8 & $23,3^{2}$ & $22,9^{b}$ & $22,7^{c}$ \\
\hline & $\pm 1,4$ & $\pm 2,5$ & $\pm 0,5$ & $\pm 1,4$ & $\pm 0,9$ & $\pm 0,8$ \\
\hline \multirow[t]{2}{*}{ Ingestão Alimentar } & 6,58 & 6,0 & 5,8 & 6,5 & 5,9 & 7,2 \\
\hline & $\pm 0,4$ & $\pm 0,6$ & $\pm 0,3$ & $\pm 0,6$ & $\pm 1,1$ & $\pm 0,8$ \\
\hline
\end{tabular}

Resultados expressos como média \pm desvio padrão de 20 (treinamento) ou 10 (destreinamento) animais por grupo. Ganho de peso treinamento = peso ao desmame - peso no último dia de treino. Ganho de peso destreinamento = peso no último dia de treino - peso imediatamente antes do sacrifício. Ingestão Alimentar treinamento = valores médios do desmame ao último dia de treino. Ingestão Alimentar destreinamento =valores médios do último dia de treino até o dia do sacrifício. $=S A L=$ solução salina, MSG = glutamato monossódico, SED = sedentário, CONT = treino contínuo, INT = treino intermitente. Diferença significativa (ANOVA PS 0,05) em relação a: a) SAL-SED, b] SAL-CONT, c] SAL-INT, d] MSG-SED.

Os animais MSG mostraram valores significativamente superiores em relação aos teores de gordura na carcaça durante todo o período experimental (treinamento e destreinamento), comparados aos grupos controle (tratados com solução salina) correspondente (Tabela 2), sem qualquer alteração na ingestão alimentar (Tabela 1). O peso do tecido adi- poso epididimal também foi significativamente mais elevado nos grupos MSG que nos SAL (Tabela 2). Ambos os protocolos de exercício atenuaram significativamente o ganho de peso dos ratos SAL e MSG (Tabela 1) e ligeiramente o teor de gordura da carcaça e o peso do tecido adiposo epididimal (Tabela 2) dos ratos MSG ao final da etapa de treinamento.

Tabela 2. Teores de gordura ( $\mathrm{g} / 100 \mathrm{~g}$ de tecido] na carcaça e peso do tecido adiposo epididimal ( $\mathrm{mg} / 100 \mathrm{~g}$ de peso corporal] dos ratos após treinamento físico e subsequente destreinamento

\begin{tabular}{lcccccc}
\hline TREINAMENTO & \multicolumn{1}{c}{} & & & \\
\hline Grupos & SAL & SAL & SAL & MSG & MSG & MSG \\
& SED & CONT & INT & SED & CONT & INT \\
\hline Teor de & 8,74 & 13,22 & 10,76 & $27,11^{\mathrm{a}}$ & $25,41^{\mathrm{b}}$ & $24,91^{\mathrm{c}}$ \\
Gordura na Carcaça & $\pm 1,81$ & $\pm 4,85$ & $\pm 3,17$ & $\pm 6,72$ & $\pm 7,73$ & $\pm 1,77$ \\
\hline Peso do T. Adiposo Epididimal & 300,53 & 424,47 & 296,38 & $916,88^{\mathrm{a}}$ & $878,21^{\mathrm{b}}$ & $780,78^{\mathrm{c}}$ \\
& $\pm 37,93$ & $\pm 266,50$ & $\pm 72,49$ & $\pm 265,17$ & $\pm 319,87$ & $\pm 239,58$ \\
\hline DESTREINAMENTO & & & & & & \\
\hline Teor de Gordura na Carcaça & 8,44 & 10,19 & 7,76 & $27,10^{\mathrm{a}}$ & $29,63^{\mathrm{b}}$ & $25,14^{\mathrm{c}}$ \\
& $\pm 2,11$ & $\pm 0,52$ & $\pm 1,40$ & $\pm 2,35$ & $\pm 4,56$ & $\pm 3,58$ \\
\hline Peso do T. Adiposo Epididimal & 344,64 & 570,88 & 426,31 & $900,75^{\mathrm{a}}$ & $1107,64^{\mathrm{b}}$ & $1048,2^{\mathrm{c}}$ \\
& $\pm 85,04$ & $\pm 216,92$ & $\pm 133,94$ & $\pm 278,74$ & $\pm 437,14$ & $\pm 261,00$ \\
\hline
\end{tabular}

Resultados expressos como média \pm desvio padrão de 5-8 animais por grupo. SAL = solução salina, MSG = glutamato monossódico, SED = sedentário, CONT = treino contínuo, INT = treino intermitente. Diferença significativa (ANOVA P $\leq$ 0,05) em relação a: a) SAL-SED, b] SAL-CONT, c] SAL-INT. 
No estudo in vitro, foi observado aumento na produção de lactato pelo músculo isolado dos ratos MSGSED em comparação aos SAL-SED. O inverso foi constatado para os MSG treinados, em ambos os protocolos, em relação aos ratos MSG-SED. Não foram observadas diferenças entre os grupos na captação e na oxidação de glicose, assim como na síntese de glicogênio, enquanto que a concentração de glicogênio no músculo dos ratos MSG-CONT foi superior à dos ratos MSG-SED (Tabela 3).

\section{DISCUSSÃO}

Os animais tratados com glutamato monossódico no presente estudo apresentaram menor peso corporal e menor estatura (comprimento focinho-ânus) que os controles, equivalentes assim como uma deposição anormalmente elevada de gordura na carcaça em ambas as etapas do estudo (treinamento e destreinamento). Isso também foi observado em outros estudos utilizando roedores tratados com MSG $(10,24,34)$.

Tabela 3. Captação de glicose ( $\mathrm{mmol} / \mathrm{g} . \mathrm{h}$ ), oxidação da glicose (mmol/g.h), síntese de glicogênio (mmol/g.h), produção de lactato ( $\mathrm{mmol} / \mathrm{g} . \mathrm{h}$ ] e teor de glicogênio $(\mathrm{mg} / 100 \mathrm{mg}$ ) em músculo isolado após treinamento e subseqüente destreinamento.

\begin{tabular}{|c|c|c|c|c|c|c|}
\hline \multicolumn{7}{|l|}{ TREINAMENTO } \\
\hline Grupos & $\begin{array}{l}\text { SAL- } \\
\text { SED }\end{array}$ & $\begin{array}{l}\text { SAL- } \\
\text { CONT }\end{array}$ & $\begin{array}{l}\text { SAL- } \\
\text { INT }\end{array}$ & $\begin{array}{l}\text { MSG- } \\
\text { SED }\end{array}$ & $\begin{array}{l}\text { MSG- } \\
\text { CONT }\end{array}$ & $\begin{array}{l}\text { MSG- } \\
\text { INT }\end{array}$ \\
\hline Captação de & 3,48 & 3,09 & 3,57 & 3,26 & 3,17 & 3,26 \\
\hline Glicose & $\pm 0,96$ & $\pm 0,40$ & $\pm 0,61$ & $\pm 0,81$ & $\pm 0,58$ & $\pm 0,50$ \\
\hline Síntese de & 1,22 & 1,05 & 1,21 & 1,16 & 1,12 & 1,02 \\
\hline Glicogênio & $\pm 0,46$ & $\pm 0,46$ & $\pm 0,25$ & $\pm 0,72$ & $\pm 0,68$ & $\pm 0,26$ \\
\hline Produção de & 0,91 & 1,29 & 1,18 & $1,69^{2}$ & $0,86^{b}$ & $0,78^{b}$ \\
\hline Lactato & $\pm 0,35$ & $\pm 0,37$ & $\pm 0,71$ & $\pm 0,78$ & $\pm 0,39$ & $\pm 0,18$ \\
\hline Oxidação de & 7,98 & 7,18 & 10,19 & 7,72 & 5,10 & 8,22 \\
\hline Glicose & $\pm 2,9$ & $\pm 2,46$ & $\pm 5,23$ & $\pm 2,07$ & $\pm 1,24$ & $\pm 2,36$ \\
\hline Teor de & 0,40 & 0,50 & 0,40 & 0,42 & $0,62^{d}$ & 0,48 \\
\hline Glicogenio & $\pm 0,12$ & $\pm 0,06$ & $\pm 0,11$ & $\pm 0,15$ & $\pm 0,23$ & $\pm 0,12$ \\
\hline \multicolumn{7}{|c|}{ DESTREINAMENTO } \\
\hline Captação de & 3,36 & 3,31 & 3,25 & 3,51 & 3,32 & 3,48 \\
\hline Glicose & $\pm 0,33$ & $\pm 0,42$ & $\pm 0,42$ & $\pm 0,59$ & $\pm 0,38$ & $\pm 0,31$ \\
\hline Síntese de & 2,74 & 1,49 & 2,10 & 1,75 & 1,44 & 1,22 \\
\hline Glicogênio & $\pm 1,95$ & $\pm 0,49$ & $\pm 1,40$ & $\pm 1,78$ & $\pm 1,20$ & $\pm 0,73$ \\
\hline Produção de & 1,33 & 0,82 & 1,11 & 1,17 & 1,10 & 0,71 \\
\hline Lactato & $\pm 0,42$ & $\pm 0,32$ & $\pm 0,62$ & $\pm 0,55$ & $\pm 0,38$ & $\pm 0,25$ \\
\hline Oxidação de & 8,14 & 7,27 & 8,10 & 9,35 & 6,42 & 7,10 \\
\hline Glicose & $\pm 2,26$ & $\pm 0,81$ & $\pm 2,77$ & $\pm 1,61$ & $\pm 2,69$ & $\pm 2,60$ \\
\hline Teor de & 1,39 & 1,16 & 1,52 & 1,28 & 1,72 & 1,63 \\
\hline Glicogênio & $\pm 0,36$ & $\pm 0,29$ & $\pm 0,44$ & $\pm 0,40$ & $\pm 0,50$ & $\pm 0,33$ \\
\hline
\end{tabular}

Resultados expressos como média \pm desvio padrão de 9-10 fatias de músculos por grupo. SAL = solução salina, MSG = glutamato monossódico, SED = sedentário, CONT = treino contínuo, INT = treino intermitente. Diferença significativa (ANOVA P $\leq 0,05$ ) em relação a: a) SAL-SED, b] MSG-SED.

O acúmulo excessivo de tecido adiposo nesses animais parece estar relacionado a um desbalanço entre respostas lipolíticas e atividades lipogênicas (10). Marmo et al. (25) e Dolnikoff et al. (10) sugeriram que a obesidade induzida por MSG consiste numa alteração metabólica caracterizada por aumento na capacidade de transporte de glicose e de síntese de lipídeos pelo tecido adiposo, resultado de um aumento na sensibilidade à insulina.

Tem sido relatado que ratos tratados com MSG são hipoativos e o desenvolvimento da obesidade nestes foi relacionada ao menor gasto energético em certos 
períodos do dia $(39,41)$. A obesidade nesses animais tem sido associada também a um aumento da eficiência alimentar (9). Animais MSG usualmente apresentam menor temperatura corporal (41) e menor taxa metabólica basal comparativamente aos animais eutróficos $(4,9,27)$. Além disso, de acordo com diferentes autores, o desenvolvimento da obesidade em ratos tratados com MSG no período neonatal, ocorre na ausência de hiperfagia e sem excessivo ganho de peso $(1,4,10,30,39)$.

Em resumo, os resultados referentes ao acúmulo de gordura na carcaça e ao crescimento somático indicam que, no presente estudo, o desenvolvimento da obesidade induzida pelo MSG processou-se conforme descrito na literatura.

Em estudos anteriores, demonstrou-se que o rato obeso pelo tratamento com MSG é um modelo adequado para o estudo dos efeitos metabólicos do exercício na obesidade (13). Dessa forma, no presente estudo, avaliou-se o efeito de dois programas distintos de treinamento sobre a adiposidade corporal e o metabolismo muscular da glicose nesse modelo. O teor de gordura na carcaça e o peso do tecido adiposo epididimal dos animais MSG treinados pelos dois protocolos foram ligeiramente menores que os sedentários após a etapa de treinamento, confirmando os resultados obtidos por Couto (6) e Gobatto et al (13). Segundo alguns autores, o exercício físico promove elevação da lipólise no tecido adiposo pela ação de hormônios lipolíticos (glucagon, adrenalina, noradrenalina, glicocorticóides e hormônio do crescimento $(\mathrm{GH})$, que são liberados durante o exercício de longa duração (33). Dessa forma, quanto mais intenso for o exercício, maiores serão os níveis séricos de catecolaminas (32), o saldo negativo no balanço energético e o gasto energético em repouso $(17,18)$. Além disso, a carga de trabalho pode induzir alterações agudas na temperatura corporal que desencadeiam respostas termorregulatórias mais duradouras (21).

Diversos estudos têm demonstrado que atletas envolvidos com exercícios de alta intensidade apresentam elevação aproximada de 5 a 20\% no dispêndio energético durante o repouso quando comparados com indivíduos sedentários $(2,40)$.

Possivelmente a elevação da atividade simpática possa estar envolvida na gênese do aumento do dis- pêndio energético em repouso induzido pelo exercício (17). Outros estudos explicam a redução do tecido adiposo corporal, promovida pelo treinamento físico como resultado de "desbalanço" entre lipólise e lipogênese (29).

O treinamento contendo sucessivos estímulos anaeróbios talvez favoreça o maior gasto energético pósexercício por manter a taxa metabólica de repouso em níveis elevados por um longo tempo (37). Nesse período, a gordura proveniente do tecido adiposo constitui o principal substrato consumido pelo organismo, reduzindo assim o conteúdo lipídico corporal. O menor conteúdo lipídico dos animais MSG submetidos ao treinamento físico pode ser um dos fatores responsáveis pelo menor ganho de peso corporal alcançado por esses animais. Outros estudos descrevem os mesmos efeitos do exercício físico em relação à perda de peso $(6,12)$.

Em resumo, ambos os protocolos de treinamento físico foram eficazes na redução do ganho de peso corporal e dos teores de gordura da carcaça dos animais obesos.

Não foram observadas, no presente estudo, diferenças entre os grupos em relação à captação da glicose, síntese de glicogênio e oxidação de glicose nas avaliações realizadas in vitro após o período de treinamento. Contudo, diversos autores sugerem melhoria na tolerância à glicose e na resistência à insulina após treinamento físico e que esta se deve, pelo menos em parte, às adaptações musculares que aumentam a ação da insulina no transporte e utilização de glicose (28). O incremento da atividade da hexoquinase (30) e da glicogênio sintetase (3), além do aumento no número de transportadores de glicose do tipo 4 (GLUT-4), associado à sua maior eficiência para translocar-se até à membrana após o exercício, podem ser a causa destas alterações (8). Também parece contribuir para esse fenômeno o aumento da capilarização dos músculos esqueléticos $(15,16)$. Além disso, foi relatado que o acúmulo das reservas de glicogênio observado com o treinamento físico pode estar relacionado ao aumento da glicogênese e ao maior transporte de glicose por mecanismos insulino-independentes (14). As discrepâncias entre os resultados do presente estudo e aqueles relatados previamente na literatura podem ser devidas, entre outros fatores, 
a diferenças nos protocolos de treinamento. Em relação à produção de lactato, os ratos MSG-SED mostraram valores elevados em comparação ao grupo SAL-SED. Isso pode indicar maior metabolismo da glicose pela via anaeróbia no primeiro grupo. Tal alteração foi revertida pelo treinamento físico, sugerindo melhora do condicionamento aeróbio. Os efeitos causados pelo treinamento foram transitórios, pois desapareceram após o destreinamento. O conjunto dos resultados referentes ao metabolismo de glicose intramuscular precisa ser visto com cautela, pois apesar de não terem sido observadas alterações na captação, oxidação de glicose e na síntese de glicogênio em resposta ao treinamento, os ratos MSG-CONT apresentaram elevação do glicogênio quando comparados ao grupo sedentário equivalente. Mais análises são necessárias para o esclarecimento desse fenômeno.

Cheng et al (5) demonstraram que dieta hiperlipídica aumenta a capacidade de oxidação de lipídeos pelo músculo de ratos obesos exercitados por 4 semanas. Em situações de necessidade, como por exemplo o jejum de 24 horas, animais obesos tratados com dieta de cafeteria mobilizaram menos glicogênio hepático (22). Assim podemos sugerir que, apesar dos ratos MSG-CONT não terem apresentado quaisquer alterações na captação, oxidação de glicose e na síntese de glicogênio muscular, os mesmos mostraram, como possível adaptação a uma situação de necessidade energética (exercício), maior capacidade de preservação das reservas de glicogênio muscular, através de mecanismos que não são explicáveis pelas avaliações feitas neste estudo.

Em resumo, os ratos MSG mostraram maiores teores de gordura na carcaça que os SAL, comprovando a eficácia da droga em causar obesidade. Ambos os protocolos de treinamento provocaram redução na produção de lactato pelo músculo esquelético dos ratos obesos, indicando melhoria do condicionamento aeróbio desses animais. Ambos os protocolos foram eficazes em reduzir significativamente o ganho de peso dos ratos SAL e MSG e ligeiramente o teor de gordura da carcaça dos ratos MSG. Os efeitos dos dois protocolos foram transitórios, uma vez que após o destreinamento os benefícios observados foram revertidos.

\author{
CORRESPONDÊNCIA \\ Maria Alice Rostom de Mello \\ Avenida 24-A, 1515 \\ Bela Vista \\ Departamento de Educação Física \\ UNESP - Rio Claro/ SP \\ 13506-900 Brasil \\ mellomar@rc.unesp.br
}




\section{REFERÊNCIAS BIBLIOGRÁFICAS}

1. Araujo PE, Mayer J (1973). Activity increase associated with obesity induced by monosodium glutamate in mice. Am J Physiol 225: 764-765.

2. Ballor DL, Phoehlman ET (1992). Resting metabolic rate and coronary-heart-disease risk factors in aerobically and resistance-trained women. Am J Clin Nutr 56: 968-974.

3. Brau L (1997). Regulation of glycogen synthase and phosphorylase during recovery from high-intensity exercise in rat. Biochem J 322: 303-308.

4. Caputo FA, Ali SF, Wolff GL, Scallet AC (1996). Neonatal MSG reduces hypothalamic DA, $\beta$-endorphin, and delays weight gain in genetically obese (Aviable yellow/a) mice. Pharmacol Biochem Behav 53: 425-432.

5. Cheng B, Karamizral O, Noales, TD, Dennis, SC, Lambert EV (1997). Time course of the effects of a high-fat diet and voluntary exercise on muscle enzyme activity in LongEvans rats. Physiol \& Behav 61: 701-705.

6. Couto GEC (1995). Efeito do exercício físico contínuo sobre o metabolismo lipídico de ratos tornados obesos pelo tratamento com glutamato monossódico (MSG). Dissertação. Universidade Federal de São Paulo. São Paulo.

7. Damaso AR (2001). Nutrição e exercício na prevenção de doenças. São Paulo: MEDSI.

8. Dela F, Ploug T, Handberg A, Petersen LN, Larsen JJ, Mikines KJ, Galbo H (1994). Physical training increases muscle GLUT4 protein and mRNA in patients with NIDDM. Diabetes 43: 862-865.

9. Djazayery A, Miller DS, Stock MJ (1979). Energy balances in obese mice. Nutr Metab 23: 357-367.

10. Dolnikoff M, Martín-Hidalgo A, Machado UF, Lima FB, Herrera E (2001). Decreased lipolysis and enhanced glycerol and glucose utilization by adipose tissue prior to development of obesity in monosodium glutamate (MSG) treated-rats. Int J Obes 25: 426-433.

11. Dubois B, Jilles KA, Hamiltom JK, Reders PA (1956). Colorimetric method for determination of sugar and related substances. Analytical Chem 28: 350-356.

12. Forbes GB (1992). Exercise and lean weight: the influence of body weight. Nutr Rev 50: 157-261.

13. Gobatto CA, Mello MAR, Souza CT, Ribeiro IA (2002). Monosodium glutamate obese rat as model for the study of exercise in obesity. Res Commun Mol Pathol Pharmacol 111: 89-102.

14. Henriksen EJ (1996). Role of glucose transport in glycogen supercompensation in reweighted rat skeletal muscle. Am J Physiol 80: 1540-1546.

15. Houmard JA, Shinebarger MH, Dolan PL, Leggett-Frazier $\mathrm{N}$, Bruner RK, Mccammon MR, Israel RG, Dohm GL (1993). Exercise training increases GLUT-4 protein concentration in previously sedentary middle-age men. Am J Physiol 264: E896-E901.

16. Hughes VA, Fiatarone MA, Fielding RA, Kahn BB, Ferrara CM, Shepherd P, Fisher EC, Wolfe RR, Elahi D, Evans WJ (1993). Exercise increases muscle GLUT-4 levels and insulin action in subjects with impaired glucose tolerance. Am J Physiol 264: E855-E862.

17. Hunter GR, Weinsier RL, Bamman MM, Larson DE (1998). A role for high intensity exercise on energy balance and weight control. Int J Obes Relat Metab Disorders 6: 489-493.
18. Imbeault P, Saint-Pierre S, Alméras N, Tremblay A (1997). Acute effects of exercise on energy intake and feeding behavior. Brit J Nutr 77: 511-521.

19. Jacobs I., Esbjornsson M, Sylve C, Holm I, Jansson E (1987). Sprint training effects on muscle myoglobin, encimes, fiber types, and blood lactate. Med Sci Sports Exerc 19: 368-374.

20. James DE, Kraegen EW, Chisholm D (1984). Effect of exercise training on whole-body insulin sensitivity and responsiveness. J Appl Physiol 56: 1217-1222.

21. Jéquier E, Tappy L (1999). Regulation of body weight in humans. Physiol Rev 79: 451-480.

22. Lladó I, Pons A, Palou A (1997). Fatty acid composition of Brown adipose tissue in dietary obese rats. Biochem $\mathrm{Mol}$ Biol Int 43: 1129-1136.

23. Lowry OH, Rosebrough NF, Farr AL, Randal RJ (1951). Protein measurement with the folin phenol reagent. J Bio Chem 193: 265-275.

24. Machado UFE, Saito M (1995). The effect of adipose cell size on the measurement of GLUT-4 in white adipose tissue of obese mice. Br J Med and Biol Res 28: 369-376.

25. Marmo MR, Dolnikoff MS, Kettelhut IC, Matsushita DM, Hell NS, Lima FB (1994). Neonatal monosodium glutamate treatment increases epidymal adipose tissue sensitivuty to insulin there-month old rats. Br J Med Biol Res 27: 1249-1253.

26. Mello MAR, Souza CT, Braga LR, Santos JW, Ribeiro IA, Gobatto C (2001). A.Glucose tolerance and insulin action in monosodium Glutamate (MSG) obese exercise-trained rats. Physiol Chem Phys and Med NMR 33: 63-71.

27. Moss D, Ma A, Cameron DP (1985). Defective thermoregulatory thermogeneses in monosodium glutamate - induced obesity in mice. Metabolism 34: 626-630.

28. Nakai N (1996). Exercise training prevents maturationinduced decrease in insulin sensitivity. J Appl Physiol 80: 1963-1967.

29. Nicklas BJ (1997). Effects on endurance exercise on adipose tissue. Exerc Sports Rev 25: 77-103.

30. Olney JW (1969). Brain lesion, obesity, and other disturbances in mice treated with monosodium glutamate. Science 164: 719-721.

31. Pilegaard H, Bangsbo J, Richter EA, Juel C (1994). Lactate transport studied in sarcolemmal giant vesicles from human muscle biopsies: relation to training status. J Appl Physiol 77: 1858-1862.

32. Pi-Sunyer FX, Woo R (1995). Effect of exercise on food intake in human subjects. Am J Clin Nutr 42: 983-990.

33. Powers SK, Howley ET, Cox R (1992). A differential catecholamine response during prolonged exercise and passive heating. Med Sci Sport Exerc 14: 453-459.

34. Ribeiro EB, Nascimento CMO, Andrade IS, Hirata AE, Dolnikoff MS (1997). Hormonal and metabolic adaptations to fasting in monosodium glutamate-obese rats. $J$ Comp. Physiol B 167: 430-437.

35. Scalfani A (1984). Animal models of obesity: classification and characterization. Int $J$ Obes 8: 491-508.

36. Silva MP, Marcondes MCG, Mello MAR (1999). Exercício aeróbio e anaeróbio: efeitos sobre a gordura sérica e tecidual de ratos alimentados com dieta hiperlipídica. Rev Bras Ativ Fís Saúde 4: 43-56.

37. Sjodin AM, Forslund AH, Westerterp KR, Andersson AB, Forslund JM, Hambraeus LM (1996). The influence of physucal activity on BMR. Med Sci Sports Exerc 28: 85-91. 
38. Sjörgreen B, Nordenskjold T, Holmgren H, Wollerstrom J (1938). Beitrag zur Kentnis des le berrrhythmik. Pflügers Archiv fuer die Gesamte Physiologie des Menschen und der Tiere 240: 247.

39. Tokuyama K, Himms-Hagen H (1989). Adrenalectomy presents obesity of glutamate-treated mice. Am J Physiol 257: E139-E144.

40 . Tremblay A, Fontain E, Nadeau A (1985). Contribution of post-exercise increment in glucose storage to variations in glucose induced thermogenesis in endurance athletes. Can J Physiol Pharmacol 63: 1165-1169.

41. Yoshida T, Nishioka H, Nakamura Y, Kanaysuma T, Kondo M (1985). Reduced norepinephrine turnover in brown adipose tissue of preobese mice treated with monosodium Lglutamate. Metabolism 36: 931-938. 